\title{
ANTITUMORAL EFFECTS OF ACONITUM SOONGARICUM TINCTURE ON EHRLICH CARCINOMA IN MICE
}

\author{
(C) Alefirov A. N., Bespalov V. G.
}

The N. N. Petrov Research Institute of Oncology of the Russian Ministry of Health and Social Development, St. Petersburg, Russia

The aim of the study was estimation of antitumoral activity of tincture of Aconitum soongaricum Stapf. tubers given at various doses and schemes in BALB/C mice with Ehrlich carcinoma. Standard $10 \%$ Aconitum soongaricum tincture (AST) contained $0.08 \%$ of alkaloids was used. LD50 of AST was defined by a method of probit analysis. Ehrlich carcinoma $\left(5 \times 10^{6}\right.$ of tumor cells) was transplanted intramuscularly to 204 female mice and to 80 male mice. AST was administered intragastrically by tube at doses from LD10 to $10 \%$ from LD10 one time or daily during from 5 till 20 days and also as a metronomic therapy at doses from $12.5 \%$ to $50 \%$ from LD10 daily up to the death of mice. Effects of AST were estimated on indicators of the inhibition of tumor growth (ITG) and increase of life span (ILS) compared with control groups of mice that were given intragastrically water. As a comparison drug it was used cytostatic cyclophosphamide which was given intraperitoneally at a dose $200 \mathrm{mg} / \mathrm{kg}$ of body weight. LD50 of AST in tenfold dilution for male and female mice was $17,4 \pm 1,71$ and $20,8 \pm 1,28 \mathrm{ml} / \mathrm{kg}$ of body weight, accordingly. LD10 of AST in tenfold dilution for male and female mice was
9.7 and $16.3 \mathrm{ml} / \mathrm{kg}$ of body weight, accordingly. In female mice the most efficient inhibitions of the Ehrlich carcinoma growth were found under administrations of AST at LD10 dose daily within 5 days (maximal statistically significant ITG was $59.1 \%$, ILS was $9.3 \%$ ) and at a dose of $25 \%$ from LD10 daily within 20 days (maximal statistically significant ITG was $43.3 \%$, ILS was $9.8 \%$ ). The metronomic therapy in female mice was the most efficient by daily administration of AST at a dose of $12.5 \%$ from LD10 (maximal statistically significant ITG was $40.1 \%$, ILS was $8.8 \%$ ). In male mice the most efficient antitumoral action was found at application of AST at a dose of $25 \%$ from LD10 daily within 20 days (maximal statistically significant ITG was $50.0 \%$, ILS was $20.9 \%$ ). Antitumoral effects of AST at these most effective schemes of application were comparable with antitumoral effect of cyclophosphamide. AST is perspective for clinical use as an anticancer remedy. The most efficient are short-term courses of administration of AST at maximal tolerable doses and long courses of administration of AST at doses from $12.5 \%$ to $25 \%$ from LD10.

\section{REPRODUCTIVE TOXICITY OF OIL EXTRACT OF SCHISANDRA CHINENSIS SEEDS}

\section{(ㄷ Avdeeva O. I., Makarenko I. E., Makarov V. G., Simanovskaya M. S.}

\author{
St-Petersburg Institute of Pharmacy, Russia
}

The aim of this study was to evaluate the reproductive toxicity of oil extract of Schisandra chinensis seeds. Generative function, embryo- and fetotoxicity were tested. The oil extract was administered in two doses 50 and $1000 \mathrm{mg} / \mathrm{kg}$ per os to male rats during 60 days period and 15 days period to female rats. The results shown that the oil extract in doses 50 and $1000 \mathrm{mg} / \mathrm{kg}$ had no toxic effects on the male generative function and there was no toxic effects on reproductive function in female rats. Administration of oil extract in doses 50 and $1000 \mathrm{mg} / \mathrm{kg}$ did not lead to embryotoxic and terato- genic effects evaluated in pregnant female rats in the antenatal period. The physical state, sensory-motor reflexes and behavioral responses of rat progeny were not changed after the oil extract administration. Thus, the results of this study shown that there was no toxic effects after the administration of oil extract of Schisandra Chinensis seeds. In particular, the administration of oil extract in doses 50 and $1000 \mathrm{mg} / \mathrm{kg}$ did not affect the generative function of male rats, and did not cause the embryo and fetotoxicity observed in the antenatal and postnatal periods. 